\title{
Narcissism and Political Orientations
}

\author{
Peter K Hatemi \\ 307 Pond Lab, University Park, PA 16803 \\ phatemi@gmail.com \\ Zoltán Fazekas \\ Postboks 1097 Blindern, 0317 Oslo \\ zoltan.fazekas@gmail.com
}

\section{Pre-publication version of:}

Hatemi, Peter K., and Zoltán Fazekas. "Narcissism and Political Orientations." American Journal of Political Science62, no. 4 (2018): 873-888.

The final version might differ. Please use/cite version available at the Publisher's website: https://doi.org/10.1111/ajps.12380

Acknowledgements: We thank Rose McDermott for her wit and always brilliant commentary and Barry Richards for his insight on the topic. We also thank Erik Gahner Larsen and Juraj Medzihorsky for their added attention to detail. This work would not have been possible without the participants and Padi Joseph at YouGov. Finally, we wish to thank the anonymous referees, who truly helped improve the article. 


\section{Narcissism and Political Orientations}

Abstract: The connections between narcissism and political orientations have been theorized by scholars, and increasingly evoked by political parties, politicians, public intellectuals, and the media. Yet surprisingly little research has been undertaken to empirically asses the veracity of these claims. We address this lacuna by identifying the relationship between narcissism, political ideologies and partisanship in a nationally representative sample taken days before the 2016 US Presidential election. Overall, we find those on the left and right are equally narcissistic. However, liberals and conservatives differ in which dimensions drives their narcissism. Specifically, we find that the Entitlement facet of narcissism is uniformly related to more conservative positions, while Exhibitionism is related to more liberal values, including political party identification. Narcissism, as a complex multidimensional construct, has an important role in understanding political ideology.

Replication Materials: The data, code, and any additional materials required to replicate all analyses in this article are available on the American Journal of Political Science Dataverse within the Harvard Dataverse Network, at: https://doi.org/10.7910/DVN/9IKGYY

Word count: 9,440 including references, tables, figures and footnotes 


\section{Narcissism and Political Orientations}

A substantial body of research finds a connection between narcissism and political elites (Watts et al. 2013). As Post $(1993,99)$ eloquently articulated: "It is probably not an exaggeration to state that if individuals with significant narcissistic characteristics were stripped from the ranks of public figures, the ranks would be perilously thinned, for the upper levels of government and industry are filled with "successful narcissists"'”. However, one area in which there is a dearth of empirical research, and certainly no thorough understanding, is the connection between narcissism and political orientations in the mass publics. This is a notable absence given the extraordinary amount of rhetoric promulgated by political elites and parties, and theoretical propositions by scholars and public intellectuals that connect narcissistic traits to both liberal and conservative values (de Zavala, Cichocka and Bilewicz 2013; Economist 2016a; Lasch 1979; Lilla 2016; McAdams 2016).

Narcissism is not simply a hyper-concern with one's self; it is a distinct construct that groups an interrelated set of dispositions containing views of self and others, cognitive styles and motivations that guide behaviors, and is a normal part of one's identity (Cramer 1997;

Rhodewalt and Morf 1995). Central to modern theories of human identity is the notion that individuals have a need to maintain a positive view of self, and thus engage in self-enhancement and defensive behavior to protect one's identity (including group identity), preserve self-esteem and agency, maintain status, and secure instrumental and material benefits (de Zavala, Cichocka and Bilewicz 2013; Hepper, Gramzow and Sedikides 2010; Morf, Horvath and Torchetti 2011). All of these processes are narcissistically regulated. At the same time, intuitions about the self reflect ideological and partisan values, bridging the gap between ideology as a values construct and ideology as an identity construct (Devine 2015; Inglehart 1990; Newman, Bloom and Knobe 2014). Here we argue that narcissism may serve as an organizing temperament that can be 


\section{Narcissism and Political Orientations}

employed to understand the dynamics of political orientations. Individuals regulate their views of self and others, and secure benefits through such mechanisms as sense of entitlement, ego aggrandizement, exploitation, display behavior, authority-seeking, and self-interest.

We begin by identifying the social-psychological construct of narcissism as a multidimensional trait that is mostly normally distributed in the population. We then articulate how its components reflect many of the basic foundations of political ideologies. Extant research proposes equally strong but different pathways of how narcissism should be related to both liberalism and conservatism. When deconstructing narcissism into its underlying components, including Authority-seeking, Self-sufficiency, Superiority, Exhibitionism, Exploitativeness, and Entitlement (Raskin and Terry 1988), there are both explicit and implied expectations that certain facets should reflect or co-constitute with ideological positions in predictable ways. That is, those on the left and right should be equally narcissistic but differ in which facets of narcissism drive the relationship. We test these hypotheses through a nationally representative study and find that those who are more entitled hold more conservative positions across ideological and partisan dimensions, while those who are more exhibitionist hold more liberal values.

\section{Narcissism}

There is no single "right" way to operationalize narcissism. Rather, there are several approaches that are more or less advantageous depending on their use. Here we focus on the well-established social-psychological construct of narcissism (Social Narcissism going forward) that appears widely in the literature and is supported by decades of research (Campbell et al. 2005; Raskin and Terry 1988; Twenge and Foster 2010). This view conceptualizes narcissism as a normally distributed trait in the population for which, unlike its clinical cousin, pathological 


\section{Narcissism and Political Orientations}

narcissism $^{1}$, there is no discrete cut-off for being a narcissist. Rather, everyone has some degree of narcissism to greater or lesser extents, akin to other temperament traits. While social and pathological narcissism share parts of their typology, and are characterized by the tendency to be entitled and to exploit others for personal gain, there are thematic differences between them (Miller et al. 2011). Social Narcissism emphasizes more of the "Grandiose" aspects of narcissism, including traits related to arrogance, demand for attention, exploitativeness, aggression and dominance, whereas pathological narcissism exhibits more of the "Vulnerable" aspects of narcissism reflecting the "expression of psychological dysfunction characterized by fragile self-esteem, emotional instability, and internalizing pathology" (Ackerman et al. 2011, 68). This is not to say that both forms do not capture some part of the other, but rather that their emphasis differs. This difference is important because while both Grandiose and Vulnerable narcissism can often result in similar behavioral outcomes, the pathways and motivations by which behaviors emerge differ. Individuals who exhibit entitled, exploitative or aggressive behaviors due to higher Grandiose narcissism do so more for instrumental reasons related to status, dominance, power and personal gain; whereas individuals higher on Vulnerable narcissism may behave in similar ways, but due so more because of affective dysregulation linked with self-esteem and traumatic childhood experiences (for a thorough explication, see Miller et al. 2011). The combination of operating on a normal continuum and stronger focus on material benefits and instrumental motivations makes the socio-psychological construct of

${ }^{1}$ Psychiatric approaches conceptualize Narcissism as a personality disorder (NPD), which is extremely rare (Kernberg 1986). 


\section{Narcissism and Political Orientations}

narcissism well suited to identify relationships with traits that emerge in the general population, and for political orientations in particular.

Narcissism has both positive and negative qualities. Those higher in narcissism have higher views of themselves and groups they belong to and see themselves as better than others and more deserving. At the same time, they are more agentic, confident, extraverted, innovative, and self-sufficient with higher approach-orientations and advanced interpersonal skills, including charisma (Campbell et al. 2005). They have a stronger sense of entitlement operating within and across groups and a stronger desire for control, power and esteem. This sense of entitlement leads to a belief in one's right to exploit others, less empathy, a focus on relative gains and a lack of regard for the needs of others, with greater use of display behavior and manipulation for personal gains. Simultaneously, they crave, demand and exploit opportunities to gain the admiration of others, have a stronger need to win and pursue leadership positions. In this way, narcissism serves as an important component of identity regulation which results in positive feelings about the self and groups they belong to, while also fulfilling status, instrumental and material desires.

The Narcissistic Personality Inventory ("NPI", Raskin and Terry 1988) is the most common measure for Social Narcissism and is comprised of forty questions which capture the aforementioned traits through seven facets (Authority-seeking, Entitlement, Exhibitionism, Exploitativeness, Self-sufficiency, Superiority and Vanity). The amalgamations of these traits

form an overall narcissism score that is unimodal and mostly normally distributed. A consensus has formed, however, that while it still may be useful to explore the greater construct by summing all the measures into a single narcissism score, it is both valuable and necessary to 


\section{Narcissism and Political Orientations}

explore the individual facets of narcissism separately because the composite NPI score may conflate adaptive and maladaptive forces (Miller et al. 2011).

The more socially adaptive facets (Barry, Frick and Killian 2003) are Authority-Seeking, which reflects a person's desire for power and self-perceived leadership ability and SelfSufficiency which reflects how much one relies upon their own abilities to meet their needs and goals. Individuals who score higher on these dimensions have greater agency, self-esteem, and self-awareness but lower levels of social anxiety (Rhodewalt and Morf 1995). These dimensions of narcissism are believed to measure some combination of psychological resilience and social potency (Ackerman et al. 2011).

The remainder are the more socially maladaptive traits: Entitlement captures the belief that one is inherently deserving of benefits and special treatment, including compliance with one's wishes. Exploitativeness reflects one's willingness to exploit others in order to achieve their goals. Superiority measures the degree one, and by extension one's group, believes they are better than others. Exhibitionism captures one's need to be the center of attention, often at the expense of others; this includes expecting greater attention be given to one's issues, opinions and values. Vanity reflects self-admiration and desire for others to see one as attractive in all ways. Those who score higher on these five facets tend to be more self-conscious, anxious, exhibit greater actual-ideal discrepancies and mood variability, but have lower self-esteem and concern for others (Emmons 1987; Rhodewalt and Morf 1995).

There remains some debate, however, as to the optimal number of factors to explore independently. Emmons (1984) supports condensing the seven factors into four dimensions: Exploitative/Entitlement, Leadership/Authority, Self-Absorption/Self-Admiration and Superiority/Arrogance. Ackerman et al. (2011), however, suggests by reducing the 40 -items to 


\section{Narcissism and Political Orientations}

25, only three dimensions are needed, keeping Entitlement/Exploitativeness and Leadership/Authority but collapsing the remainder into Grandiose Exhibitionism. In this exploration we analyze the original seven factors independently as suggested by Raskin and Terry (1988), for completeness and transparency, and to reduce the possibility of any conflation of adaptive and maladaptive influences. In addition, many of the proposed theoretical connections identified in the extant literature between narcissism and political orientations focus on the individual facets. For comparative purposes, and to recognize the theoretical contribution of Ackerman et al. (2011), we also explore their alternative three factor structure.

Regardless of its operationalization, Social Narcissism's combination of the social and personal makes the construct attractive to aid in understanding political values. Politics provides a lightning rod to both mobilize narcissistic tendencies and a platform to act upon them, interpersonally and publicly, even if only in the virtual sphere. Choices are presented as favoring one person, demographic, party or group over another and political issues are among those that people care most about and reflect the very things that people see as related to their own sense of identity and personal well-being (Inglehart 1990; Iyengar and Westwood 2015). Issues surrounding how society should work, justice, security, self-image, resources, liberties, freedoms, rights, and benefits rest at the core of both political orientations and narcissism. Political parties, elites and campaigns construct messages to make the political personal. Issue positions are sold and structured to make clear that "these issues" are about "you" or the group you belong too. Lasswell (1965) built a foundation upon the understanding that the public transcribes world concerns to personal concerns; but perhaps then Speaker of the House Nancy Pelosi's (2010) remarks ahead of the historic vote to give the US government control over national health care provides the most poignant example: "Speaker, Tip O'Neill once said: 'All 


\section{Narcissism and Political Orientations}

politics is local.' And I say to you tonight that...all politics is personal." The very foundation of having a coherent set of beliefs that guides one's decisions (i.e., ideology) also partially reflects the core of narcissism. Political attitudes and ideologies are not just how one feels about how they should live but demands that others should live the same way. In this way, there is an implied sense of righteousness, superiority and self-worth that one's political values and orientations are the only ones that are acceptable.

However, if this is all there was to the relationship, then narcissism should have a connection with opinionation or strength of attitudes only. Those higher in narcissism should be evenly distributed across the left and right: the choice would have little to do with how one views self or society, only that it meets one's ego, material and instrumental needs in whatever context they are in. In this way, those higher in narcissism would simply choose the ideological or partisan position that best met their need for status, benefits and control, and this would differ by environmental conditions and power of the relative groups. While this may be true in one respect, narcissism is a multidimensional construct, and there are a substantial number of theoretical propositions that propose that Social Narcissism's facets should be differentially related to liberal and conservative values. It is to these propositions we now turn.

\section{Narcissism and Ideology}

Perhaps some of the most important developments bringing to light the possible connection between narcissism and political ideologies began with the highly influential works of Adler $(1964,1970)$ and Hardin (1968). Extending the construction of narcissism from one that emerges through childhood development, they included the problems and pressures of everyday life, particularly those associated with modern society. They suggested that the highly competitive and materialist culture of capitalism glorified status, material desires, selfishness and 


\section{Narcissism and Political Orientations}

egotism, which led to a decline in community, empathy, and shared fate. Tom Wolfe (1976) and Christopher Lasch (1979) further developed and popularized this view in their celebrated works, "The Me Decade" and The Culture of Narcissism, respectively; they argued that the radical social and economic changes that occurred post WWII, continuing into the 60's and 70's and beyond, resulted in heightened narcissistic activation that manifest through political action. The persistent state of conflict, the increased competition of everyday life and the emphasis on material wealth, combined with the real chance that one's life might end by a nuclear war (or a terrorist today), are suggested to bring out heightened self-interested narcissistic tendencies in everyone to varying degrees; instead of being future-oriented, narcissistic activation moves individuals to become increasingly inner-directed, focused on personal gratification and living with only the present in mind (Cushman 1990).

\section{Liberalism and Narcissism}

Lasch and Inglehart $(1977,1990)$ proffer or at least imply an explicit link between narcissism and liberalism. They argued that the rise of self-awareness and human potential movements led to an increase in individualism and identity-based interest groups that manifest politically as liberalism; and narcissism captures a form of extreme individualism. The rights of the individual, including sexual liberties and freedoms, and moral relativism, or at least moral tolerance, remain at the center of domestic liberalism (Lakoff 2010). Research finding both liberals and narcissists are more approach-oriented and sexually adventurous suggests that those higher in narcissism will have more liberal views, including those on social and sexually related policies (Baughman et al. 2014; Hatemi, Crabtree and McDermott 2017; Janoff-Bulman 2009). For example, a more fatalist view of the world reduces the cost of social sanction from removal of mores and inspires a living "for the now" mind-set, which increases social liberalism. In this 


\section{Narcissism and Political Orientations}

way, the Exhibitionist facet of narcissism appears a strong candidate to correlate with liberalism. At the same time, liberalism also advocates that society is responsible for other's welfare, and this has been argued to reflect the opposite of Entitlement.

Equally interesting is the proposed connection between narcissism and liberalism that resides in identity politics: the political grouping of interests on the basis of ethnic, cultural, racial, sexual or other demographic and categorical claims that emerged in conjunction with the rapid transformations of Western society at the end of the 20th century, including the reorganization away from income and social class-based political parties (Bernstein 2005). Identity politics is widely considered a platform of the political left (Bennett 2012; Inglehart 1990). It reflects a demand for benefits and rights be awarded based upon a political identity; historically these groups been tied to liberal positions and the Democratic party.

The demand for group benefits, the inherent or implied superiority of one's person or groups' needs over another, explicit motivation and demands to makes one's views, positions and group known, and desire to be at the center of the issue space, arguably reflect the narcissistic dimensions of Superiority, Exhibition and Exploitation. Furedi (2016), for example, provides a compelling case there is no better example of this relationship than the political and ideological developments that have manifested in public discourse and higher education over the last decade. The phenomena that those in the left increasingly fragment to focus on the most reduced combinations of ethnicity, citizenship, class, gender, sex, sexuality, age, income, and other demographic categories as markers of distinct political identities; the increased commonality of individuals explicitly assigning such micro-identities to themselves when speaking (e.g., "As a ...) ; the invention of "safe spaces" to restrict public speech that does not reflect modern liberal values (McLaughlin 2017); the search for "micro-aggressions" in common 


\section{Narcissism and Political Orientations}

discourse, such that phrases that have been used historically to positively describe Americana, including "America is the land of opportunity" have been deemed offensive and banned by some universities for the possibility they might be considered insensitive to those who have not been able to realize such opportunity (Volokh 2015); and the inventions of "trigger warnings" that impede discussion, which is the heart of a healthy democracy, are all championed by the left (Lukianoff and Haidt 2015). It has been argued that these happenings signify the increased presence of individuals' who desire to reflect on self, have a special or unique identification, have an audience, receive benefits specific to their identity and impose a form of dominance and social control on others (Campbell and Manning 2014,2016), "bear[ing] all the hallmarks of cultural narcissism" (Furedi 2016, 77).

Perhaps the most widely purported, yet never empirically identified relationship between narcissism and liberalism is the belief that those who espouse liberal ideas believe themselves to be superior. Hofstadter $(2011(1960), 13)$ for example, reflected on the view that to be conservative was to be "out of touch" with reality. The term "liberal superiority" has been used extensively by elites on both the left and the right. Public intellectuals consistently label conservatives and conservative platforms as "stupid", "narrow minded" and "ignorant". There are a number of academic works that propose they have found evidence of the same. Kanazawa's (2010) declarations that liberals are both more intelligent and evolutionary advanced than conservatives is only one of the most celebrated and highly debated of these claims (e.g., Deary, Batty and Gale 2008). Political leaders, such as former Vice President Al Gore (2006), claim that conservatives lack reason and are more driven by emotional factors. Scholarly research has proffered that conservatives rely on lower-cognitive-load thought processes, and that the right amygdala, an area of the brain associated with emotion and management of fear and uncertainty, 


\section{Narcissism and Political Orientations}

is more active in conservatives, while liberals have greater activity in the anterior cingulate cortex, which is believed to be related to error detection, cognitive complexity, and weighing of competing choices (Eidelman et al. 2012; Weissflog et al. 2013). Haidt and Graham $(2007,113)$ note this type of evidence has been used to "make conservatives look rigid, authoritarian, and dumb".

It is a great leap however from being in a category that is seen as having a more "desirable trait" to believing oneself superior; or to apply views by elites and academics to the general public. Given the large amount of discussion, there are surprisingly few empirical studies exploring the relationships between liberalism and narcissism. Rothman and Lichter (1985) find business elites are more narcissistic and more socially liberal, suggesting a correlation between the two, but their sample and analyses were limited. Toner et al. (2013) found that those on the left and the right equally see their own political views as superior, but the study did not address the question of belief of superiority of self or group, only one's views. Given this distinction, the findings are unsurprising; it would be illogical for one to have a belief on an issue but think the opposite belief is superior. In this light, they provide little traction to confirm or reject the hypothesis that liberalism and narcissism are uniquely related.

\section{Conservatism and Narcissism}

Certainly, extant theory and research appears to make a reasonable case that narcissism and liberalism could be related. However, there is equal evidence that conservatism and narcissism should be related. And while the past half century of research has provided evidence in support of Adler, Hardin and Lasch's reasons for narcissistic activation, including economic success, physical and financial insecurity, greater liberties, increased wealth, and materialistic culture (Twenge and Campbell 2009), these appeared to move people to more conservative 


\section{Narcissism and Political Orientations}

positions as much as liberal ones, opposite Lasch's (1979) projections. Empirical research finds that increased conservatism may serve as a coping mechanism for the stresses and dangers of the modern world (Jost et al. 2007), and conservatives are the ones more likely than liberals to perceive the world as a dangerous place (Duckitt 2001). An increasingly dangerous world however, or perception of it, is also believed to have a profound influence on the development and manifestation of one's view of self and pursuit of benefits. According to Terror Management Theory, defensive processes become more pronounced under conditions of perceived conflict and resource scarcity, which primes individuals to be more anxious, selfinterested and focus on material and instrumental benefits (Arndt et al. 2004). In this way, while threats to self, identity, status and success serve as the impetus, and conservatism may be a coping mechanism (Jost et al. 2007), narcissism may provide an important middle layer in the underlying psychology that captures those who seek to regulate identity or bolster status. Scholarly research points toward this; de Zavala, Cichocka and Bilewicz (2013) for example, find devaluating the out-group increases in-group identification; these findings map strongly to narcissism's general theory - that those higher in narcissism will act in a manner to protect themselves, particularly when their identity, status, or needs are threatened (Bushman and Baumeister 1998; Lambe et al. 2016).

Those higher in conservatism tend to score higher on independence, personal responsibility and self-reliance, focus more on preventing negative outcomes, believe that competition is good, show more in-group preference and a greater desire for hierarchy and control (Carney et al. 2008; Janoff-Bulman 2009; for a review, see Hatemi and McDermott 2016). The narcissistic facets of Self-sufficiency, Authority, Entitlement, Exploitation, and Superiority reflect these tenets of conservatism. For example, the Superiority and Authority- 


\section{Narcissism and Political Orientations}

seeking facets are related to general competitiveness (Raskin and Terry 1988) and competition seeking is often used to defend against negative self-views or ensure benefits by attempting to increase one's value through enhancing status, power, and self-esteem (Luchner et al. 2011).

One dimension of conservative orientations, Social Dominance (Pratto et al. 1994), which surrounds views of intergroup relations, specifically how much one prefers relations to be hierarchical and to order social groups along a superior-inferior dimension, implies an important connection between narcissism and conservatism. Individuals who desire to either maintain or increase the status and resource differences between their in-group and all other groups, who are more power-seeking, dominant, and tough, with lower empathy, tend to be more conservative on most attitudinal domains. The narcissistic traits of Entitlement, Exploitativeness, Selfsufficiency and Superiority all correlate with the facets shared between conservatism and Social Dominance. Bizumic and Duckitt (2008) for example, find that narcissism predicts ethnocentrism and in-group superiority, both traits being related to conservative orientations. de Zavala, Cichocka and Bilewicz (2013) find that narcissism is related to high private but low public self-esteem which predicts higher perceived threat from, and aggression toward, outgroups, including denial of resources, reflecting Entitlement. That is, narcissism at the individual level can be extended to group affiliation and intergroup relations (de Zavala et al. 2009). In this way, the identity driven emotional investment in an inflated image of an in-group is ingratiated upon the self. At the same time, the relationship between narcissism and conservatism is proffered to go beyond out-group derogation for identity enhancing needs. Key tenets to conservatism are individual responsibility, self-sufficiency and compliance. This is important because those higher in "groupish" behavior are more likely to justify inequality and 


\section{Narcissism and Political Orientations}

resource control using these reasons, which in turn strongly reflect the adaptive narcissistic facet of Self-sufficiency and the maladaptive facet of Entitlement.

\section{Hypotheses}

The extant literature suggests that both liberalism and conservatism should be related to narcissism, but for different reasons. That is, those on the left and right should not meaningfully differ on overall narcissism. However, the facets driving the public's respective narcissism should differ systematically by ideology. More specifically, the literature reviewed provides a credible case that three facets of Social Narcissism should differentially guide left-right orientations, which we summarize in Table 1.

(Table 1 about here)

First, Exhibitionism's relationship with labeling, identity politics, individualism, desire to control the issue space, and sexual liberalism make it appear a likely candidate to be uniquely related to more liberal social attitudes and more liberal orientations generally. Equally important, we could find no theoretical connections linking Exhibitionism with conservatism. Second, the Self-sufficiency facet reflects a core tenet of conservatism and thus should be associated with more conservative orientations. Finally, the Entitlement facet, while appearing to have a limited potential to reflect liberalism through identity politics, has a much theoretically stronger proposed negative relationship with liberalism through altruism (i.e., support of entitlements to others), and a strong positive relationship with conservatism through hierarchical values, groupishness, ethnocentrism, compliance and power-seeking.

For the remaining facets, there appears separate but equally weighted evidence that they should be related to both liberal and conservative values, and therefore, similar to overall narcissism, should not provide much leverage to differentiate between the two. For example, 


\section{Narcissism and Political Orientations}

predicting the role of Exploitativeness is unclear; the theoretical connections with identity politics and sexual activity trend toward a link with economically and socially liberal values; but Exploitativeness' link with more socially dominating values, including ethnocentrism and group control of resources, trend toward more conservative orientations. The same is true for the Authority facet. While there is strong evidence that conservatism is related to Authoritarianism (Stenner 2005), narcissism's Authority facet is a completely different construct. Recall, it is focused on demand for, or seeking positions of, authority, not desire to adhere to other's authority as is the case of Authoritarianism. Superiority also has equally strong reasons to be related to both liberal and conservative values. Its relationship with identity politics, individualism and sexual satisfaction trend toward a link with economic, social and overall liberal values. At the same time, the connections with ethnocentrism, group superiority and social dominance point towards conservatism. We could find little theoretical connections with Vanity and ideologies, and thus consider analyses of this facet to be exploratory.

\section{METHODS}

The data used to empirically test our propositions was collected days before the 2016 U.S. presidential elections between 26 October and 1 November by YouGov. It is a nationally representative sample of 750 individuals using a stratified sampling frame drawn from the 2010 American Community Survey, matched with voter registration status and turnout from the 2010 Current Population Survey, and the 2007 Pew Religious Life Survey. This resulted in a sample that is representative in terms of sex, age, ethnicity, education, party identification, and ideology (for details on the sample see SI 1). 


\section{Narcissism and Political Orientations}

Narcissism: Participants were assessed by the Narcissistic Personality Inventory (NPI), which is the most widely used measure to assess non-pathological narcissism in the general population (Raskin and Hall 1981). The measure consists of 40 forced-choice dyads where respondents choose one of two opposing statements, such as: "I try not to be a show off" vs. "I will usually show off if I get the chance" (see SI 2 for exact questions). Using the recommended scoring-sheet we recoded each response so that 1 reflects endorsing the more narcissistic choice, 0 otherwise. For overall narcissism we sum these scores across the 40 items (the full NPI battery) and divide by the number of answers provided, resulting in a variable theoretically ranging between 0 (lowest narcissism) and 1 (highest narcissism). We carry out this summation based on the measurement properties conveyed by a Cronbach's alpha of 0.86 , which is consistent with previous research on the NPI. In our data, the overall NPI score has a mean of $0.28(0.17$ standard deviation), which is slightly lower than those found in most of the extant research that relied on student samples (Foster, Campbell and Twenge 2003; Trzesniewski, Donnellan and Robins 2008). This is not unexpected given that our sample is age representative of the general population and narcissism is higher in younger adults.

We calculated the seven facets of the NPI's narcissism (Authority, Entitlement, Exhibitionism, Exploitativeness, Self-sufficiency, Superiority and Vanity) as averages across the relevant items according to the scoring-sheet. We based this decision on good results from a 7factor confirmatory analysis fitted to all 40 items (Diagonally Weighted Least Squares estimation): robust $\mathrm{CFI}=0.913$; robust $\mathrm{TFI}=0.906$; robust $\mathrm{RMSEA}=0.034(0.031,0.03890 \%$ confidence interval). In SI 3 we report these results in detail with the reliability and descriptive statistics together with Ackerman et al's (2011) alternative three-factor specification. Our results comport well with extant studies, including a similar reliabilities of the Entitlement, 


\section{Narcissism and Political Orientations}

Exploitativeness and Self-sufficiency facets, which are argued to have good criterion validity despite their relatively lower internal consistency (e.g., Gentile et al. 2013).

Ideology: We use multiple measures of ideology in our analyses. First, we measure selfreported ideology with the often-used "Very liberal" to "Very conservative" scale. This measure reflects how individuals see themselves on the ideological continuum, and is a part of one's identity, anchored in social and political values (Devine 2015; Inglehart 1990). Second, we included all political attitude related questions in the survey (five). These items capture, in part, the multi-dimensional views of attitudinal ideology (Klar 2014), focusing on the economy (Public Spending), social issues (Gun Control and Police), and two in-group vs. out-group opinions (Immigration and Refugees). These items (separately) tap into different dimensions of ideology and offer a more fine-grained picture of political orientations focused on policies, compared to the self-reported single-item measure. The two types of measures, attitudinal and self-report, are meant to complement each other, rather than one of them being superior. Table 2 displays a summary of descriptive statistics and answer options and SI 4 displays the correlations between measures.

(Table 2 about here)

Party Identification and Religiosity: One central theme of previous analyses of attitudes and ideology is the role of party identification. Although the direction of the causal relationship between ideology and party identification is unresolved, if the goal is to offer a more encompassing model of ideology then a reasonable argument can be made to include the strongest correlates of ideology. Party identification is measured with the widely used $7 \mathrm{pt} \mathrm{scale}$ from "Strong Democrat" to "Strong Republican." Here we use both the full 7pt measure, and for ease of interpretation a grouped 3-point party identification (Democrat, Independent, 


\section{Narcissism and Political Orientations}

Republican) measure treated as a categorical predictor in the extended models of Narcissism and Ideology. We also include the importance of religion ("Not at all important" [23\%] to "Very important" [40\%]). Beyond party affiliation, religiosity is argued to be one of the most important predictors of political values. Including these two measures allows us to evaluate the robustness of the relationship between Narcissism and Ideology in a model that includes the strongest correlates of Ideology.

Demographics: We control for sex (1=women, 57\%), age, ethnicity (1=not Caucasian, $20 \%$ ), education ( $1=$ "some college" or more, $68 \%$ ), and family income ("Less than $\$ 10,000$ " to “\$500,000 or more”). Exact answer categories for all items are presented in SI 1.

\section{Analyses}

In the first step of our multivariate multiple regression analyses we account for the coding of our ideology measures in terms of error distributions assumed, and fit a linear regression estimated with OLS for Self-report Ideology, 7-category Party ID, Refugees, and Gun control attitudes, an ordered-logistic regression (estimated via Maximum Likelihood) for Economy, Immigrants, and Party ID (3 categories), and a binomial logistic regression for the Policing related attitudes. ${ }^{2}$ We rescale the continuous outcomes to range from 0 to 1 in order to facilitate ease of interpretation. For each of these outcomes, we fit two models: we include the full NPI along with socio-demographic controls as predictors (1), and a model including sub-facets (full NPI not included) and socio-demographic controls (2), resulting in 16 models fitted. To aid comparability between coefficients, we mean centered the continuous predictors and divided by two standard deviations (Gelman and Hill 2007). The results are summarized in Figure 1; detailed results are reported in SI 6.

2 The bivariate correlations are reported in SI 5. 


\section{Narcissism and Political Orientations}

First, we observe that once socio-demographic differences are accounted for, overall Narcissism (full NPI) does not discriminate between liberals and conservatives. We find weak and non-significant effects for overall Narcissism across the board, which is in line with our expectations. We highlight one exception, the case of attitudes towards immigrants, where we find that more narcissistic individuals report more restrictive immigration preferences. The magnitude of the effect (change of 2 standard deviation) is comparable to that associated with having at least some college education (negative).

(Figure 1 about here)

More importantly, confirming the expectations set forth in the literature, once we examine whether specific facets have unique effects on political orientations, two robust findings emerge: Entitlement is positively associated with all ideological measures (more conservative values), while Exhibitionism is negatively associated with all outcomes (more liberal values), but we note this association is not statistically significant $(<.05)$ for Immigration and Policing policies. However, after controlling for demographics, we find no support for our hypothesis regarding Self-Sufficiency's positive association with conservatism.

As we have fit a large number of models with many tests, in order to address potential multiple comparison issues, we fit two (Bayesian) hierarchical linear models, focusing on the effects of Exhibitionism and Entitlement, where we treat the type of ideology and party identification (the 3-category operationalization) as a grouping variable, and estimate the average effect of the two sub-facets in two separate models, while letting these effects vary across the outcome types. Essentially, we adopt a partial-pooling approach. While we only have seven groups (number of different outcomes) and not all of these outcomes are continuous, we believe this complimentary approach is useful to grasp the overall effect of the sub-facets, without 


\section{Narcissism and Political Orientations}

multiple comparison issues. We include the socio-demographic controls as well, but their effects do not vary across outcomes as they are not the focus of our study. Finally, we do not estimate correlations between the varying effects of the facets and the varying intercepts, given the number of groups. All outcomes are recoded to range between 0 (most Liberal/Democrat) to 1 (most Conservative/Republican).

(Figure 2 about here)

Figure 2 summarizes the core results, confirming what we reported based on the separate models: we find a significant positive average effect for Entitlement and a significant negative average effect for Exhibitionism. Overall, this second step in our analyses reinforces our confidence in the regression analyses with one potential exception. The specific effect of Exhibitionism on Refugee attitudes comes with more uncertainty, and therefore we cannot rule out that there is no effect for this attitude.

(Figure 3 about here)

Next, we assess how Narcissism performs when we seek to explain as much variation as possible; along with the socio-demographic controls for the Ideology related models we include controls for Party ID and Religiosity, whereas in models that seek to explain the variation of Party ID, we include controls for Self-report Ideology and Religiosity. We follow the same steps of first reporting results from separate models without pooling (Figure 3, SI 7) and then the results from a pooling approach (Figure 4).

Exhibitionism's negative association is significant in models including sociodemographic controls for five out of seven ideology measures. None of these effects however, remain significant once Party ID and Religiosity differences are accounted for. This is not unexpected given the very large covariation $(\mathrm{r}=0.7)$ between Party ID and Ideology. 


\section{Narcissism and Political Orientations}

Nevertheless, when controlling for Self-reported Ideology, the negative effect of Exhibitionism on Party ID does remain significant. This suggests that the covariance between Exhibitionism and various ideology measures is based on elements of ideology that covary with Party Identification.

(Figure 4 about here)

Regarding Entitlement, there is an overall positive effect across different measures of political orientation, with minor variation between outcomes in terms of effect sizes and varying degrees of uncertainty (Figure 4). That is, Entitlement has an independent relationship with Party ID and ideological values, even when they are included in the same model.

Although the literature and theoretical framework did not provide specific expectations for moderate positions, we offer further qualifiers regarding our most robust finding surrounding the relationships between Entitlement, out-group attitudes and Party ID. Here, rather than treating the outcomes as continuous or ordered categorical, we fit three multinomial logistic regressions, including all controls and Entitlement. First differences are displayed in Figure 5.

(Figure 5 about here)

The strongest ideological ordering of the Entitlement differences is for Immigration attitudes, where those scoring high in Entitlement are more likely to prefer immigrants to leave the country and also less likely to prefer policies that would allow immigrants to stay and apply for citizenship, with no effect for more moderate opinions. However, the case of Party ID is different: scoring higher in Entitlement does not translate into a statistically significantly higher likelihood of self-identifying as a Republican, although the effect is positive and substantively relevant. Rather, those scoring higher in Entitlement are much less likely to self-identify as Democrat and much more likely to be Independent. Finally, while to some extent consistent with 


\section{Narcissism and Political Orientations}

a linear interpretation and treatment of Refugee attitudes, two categories sustain these results: higher likelihood to greatly oppose refugee acceptance for higher Entitlement scores, and lower likelihood of moderately favoring this policy. However, such variation does not explain the null results for Self-report Ideology: we find no evidence for differences in Narcissism related to more extreme versus moderate ideological positions (see SI 8). Finally, we consider Ackerman et al's (2011) alternative structure of the NPI, which uses a subset of 25 items. The results generally comport with our use of the full 40-item measure with minor differences (SI 9).

\section{Limitations}

Although the sample was nationally representative, suitably powered, and utilized the most commonly accepted measures of Social Narcissism, the measures are self-report. It is possible that some participants may have provided socially desirable responses in an attempt to portray themselves more favorably. In order to influence the results, however, this favoritism would have to be systematically expressed on one side of the political spectrum, which there is no indication of. We are also reassured by research that finds those higher in narcissism are proud of it and in general, freely admit it. Konrath, Meier and Bushman (2014) have shown, for example, that agreeing with the statement, "I am a narcissist" correlates highly with narcissistic traits. A second limitation is that the study is correlational nature, precluding any determination of causality. We discuss this in more detail below.

\section{Discussion}

Politics arguably presents the ideal theatre for narcissism to be expressed: the endless trading of insults by politicians; the anxiety-laden, personalized and alarmist mobilization messages propagated by campaigns; the demands that one group's needs is more important or legitimate than others; and the intrinsic rewards people obtain from watching the champions of 


\section{Narcissism and Political Orientations}

their cause degrade their opponents, puts narcissism on display and activates it in the public like few other vehicles can. Our age has been labeled the post-truth age, where information that conflicts with one's views is justifiably questionable; it is an age of political narcissism that promotes the self over society and the superiority of one's ideas versus a plurality of voices, lacking in honesty and civility (Economist 2016b; Glasser 2016; Keyes 2004). Despite the growing amount of discussion by scholars, public intellectuals, political elites and parties, that depending on their orientation, proposes either liberal or conservative values derive from narcissism (Economist 2016a; Ghorbani et al. 2004; Lilla 2016), there has been little empirical study on the subject. This is a particularly interesting phenomena to explore, given narcissism's proposed functional connection to political ideology in general (de Zavala, Cichocka and Bilewicz 2013; Lasch 1979). Our findings from a representative sample reveal that narcissism, as a multidimensional construct, facilitates our understanding of political orientations in the mass publics, though not in ways partisans and the media have proposed.

We find that narcissism is evenly distributed across liberal and conservative orientations. While elites are projecting that narcissistic characteristics drive the views of their opponent's constituents, the data say different. Regarding the general public, liberals and conservatives are no more or less narcissistic compared to each other. Any research that may diminish pejorative assumptions about political opposites, and reduce prejudgment offers hope of a more civilized discourse and potential compromise. In addition, while there has been an intense focus on understanding the differences between liberals and conservatives, including identifying the social, psychological and biological mechanisms that produce political orientations, this study identifies an underlying psychological orientation that does not greatly differ between the left and right. We are more similar than different. 


\section{Narcissism and Political Orientations}

While narcissism's role on identity regulation and the motivations to achieve status and benefits, in most ways, operates in a similar manner across the ideological spectrum, we do find some differences, specifically on how narcissism is expressed. And again, contrary to elite and media opinions, the differences between the left and right are not between positive and negative traits, but rather, different associations with ideological positions are present only within the maladaptive facets of Narcissism. A higher sense of Entitlement is associated with more conservative positions, and this association is strongest for out-group related attitudes. An important nuance to this finding is that regarding political affiliation, it is not that Entitlement leads to being more Republican, but rather it leads away from supporting the Democratic party. Conversely, Exhibitionism, also a maladaptive facet, is related to more liberal positions, and this is most pronounced in the case of party identification. Narcissism's more socially adaptive facets, Authority and Self-Sufficiency, which aid in higher intrinsic self-esteem and agency, do not differ between the left and the right. Rather, the negative components of narcissism are expressed differentially between the left and the right. Interestingly, both Exhibitionism and Entitlement are outward facing facets. They both demand something from others.

These findings have obvious and important implications for understanding election outcomes and mobilization efforts. It appears that those who feel more entitled to certain benefits have moved away from the left, while those who are more vociferous about their entitlements and want others to recognize their needs, values and status, are more likely to self-identify as a liberal or a Democrat. These findings do appear intuitive given recent election outcomes and polling discrepancies. In the 2016 election, higher entitlement reflected the mood of the general public, certainly among the working class, which voted Republican in greater numbers. At the same time, the voice of the left was represented to a much greater extent, certainly in the media, 


\section{Narcissism and Political Orientations}

and this was reflected in polling discrepancies, where reports for Democratic support were exaggerated, while support for then candidate Trump was under-reported. While we can only speculate given the limitations of our data, there appears a likely role of narcissism on the rise of populism. Modern populism's anti-establishment views, focus on individualism, feeling of group superiority, belief in entitlement, and explicit link with identity politics (Müller 2017) map strongly to narcissism's theoretical framework. We believe this is an important avenue to explore in future research.

While identifying the direction of causation is beyond the current study, the question remains if these psychological correlates manifest through or manifest by political orientations. That is, do the more stable components of Exhibitionism lead one to be more liberal, or does a more liberal disposition and subsequent experiences rendered through the affiliation with the Democratic party make one more exhibitionist? Or are these forces mutually influential and bidirectional? The same questions apply for Entitlement. Are people who are more generally entitled drawn away from liberal values, or does being more conservative lead one to be more entitled in order protect status and secure material and instrumental benefits? Here we only scratched the surface of narcissism's potential for understanding American public opinion and political behavior. Narcissism's role in identity, self-interest, need for attention, benefit seeking, threat-response, affect, affiliation and empathy appear obvious antecedents to political participation, mobilization, efficacy, interest, and discussion. Given the evidence presented here, and the meaningful effect sizes, the need to explore narcissism's role on participatory behaviors and civic motivations is apparent.

Of additional importance, one of the more historically referenced tenets of domestic conservatism is personal and economic self-sufficiency. While elites continue to promote such 


\section{Narcissism and Political Orientations}

values, it appears that regarding the general public, liberals see themselves no less self-sufficient than those who identify as being conservative. This presents an interesting conundrum. That is, those on the right believe people in general should be more self-sufficient, particularly those on the left, while those on the left believe they are equally self-sufficient compared to those on the right. Whether this is a case of misattribution, social desirability in reporting or simply inaccurate perceptions of self or others, remains to be seen.

Finally, this investigation adds to the study of narcissism as well. There are few nationally representative samples of the NPI. In our data, we find generally better measurement properties of the NPI than those reported in some of the foundational studies that relied upon convenience samples. That is, the NPI travels well to the general population. Furthermore, in this nationally representative sample we also report lower levels of narcissism as compared to student samples, particularly Vanity, potentially nuancing some of the discussions around the widespread nature of narcissism and its consequences (Foster, Campbell and Twenge 2003; Wetzel et al. 2017).

\section{Conclusion}

We find that the same fundamental psychological mechanism can, through the combination of dispositional influences and different social experiences, produce both similar and politically opposing outcomes in ideology and affiliation. Why should the ontology of narcissism matter if overall levels remain identical across political orientations? At first glance, the outcome measures may appear similar. But this high-level view masks important features regarding not only its divergent manifestation but the function that narcissism serves for different ideologies. The findings provide evidence that two facets of narcissism, Exhibitionism and Entitlement, may constitute part of a specialized functional psychology that facilitates status 


\section{Narcissism and Political Orientations}

maintenance, instrumental needs, self-esteem regulation and identity formation through, or as a result of, different ideological orientations. The reason this may matter in wider political discourse is because it offers alternative models for successful intervention and policy compromise. Different ideological values appear to require both similar and divergent psychological needs be met in order to find a common ground for policy changes. Understanding the source and function of those needs brings us one step closer to being able to bridge the gap between those who may share more goals than they realize but differ in how they psychologically get there. 


\section{Narcissism and Political Orientations}

\section{References}

Ackerman, Robert A, Edward A Witt, M Brent Donnellan, Kali H Trzesniewski, Richard W Robins, and Deborah A Kashy. 2011. "What does the Narcissistic Personality Inventory really measure?". Assessment 1: 67-87.

Adler, Alfred. 1964. Individual Psychology of Alfred Adler: Harper Collins.

Adler, Alfred. 1970. Superiority and social interest: A collection of later writings: Northwestern University Press.

Arndt, Jamie, Sheldon Solomon, Tim Kasser, and Kennon Sheldon. 2004. "The urge to splurge: A terror management account of materialism and consumer behavior." Journal of Consumer Psychology 14(3): 198-212.

Barry, Christopher T, Paul J Frick, and Amber L Killian. 2003. "The relation of narcissism and self-esteem to conduct problems in children: A preliminary investigation." Journal of Clinical Child and Adolescent Psychology 32(1): 139-52.

Baughman, Holly, Peter Jonason, Livia Veselka, and Philip Vernon. 2014. "Four shades of sexual fantasies linked to the Dark Triad." Personality and Individual Differences 67: 47-51.

Bennett, W Lance. 2012. "The personalization of politics: Political identity, social media, and changing patterns of participation." The ANNALS of the American Academy of Political and Social Science 644(1): 20-39.

Bernstein, Mary. 2005. "Identity politics." Annual Review of Sociology 31: 47-74.

Bizumic, Boris, and John Duckitt. 2008. "My group is not worthy of me: Narcissism and ethnocentrism." Political Psychology 29(3): 437-53.

Bushman, Brad J, and Roy F Baumeister. 1998. "Threatened egotism, narcissism, self-esteem, and direct and displaced aggression: does self-love or self-hate lead to violence?". Journal of Personality and Social Psychology 75(1): 219.

Campbell, Bradley, and Jason Manning. 2014. "Microaggression and moral cultures." Comparative Sociology 13(6): 692-726.

Campbell, Bradley, and Jason Manning. 2016. "Campus Culture Wars and the Sociology of Morality." Comparative Sociology 15(2): 147-78.

Campbell, W Keith, Carrie Pierce Bush, Amy B Brunell, and Jeremy Shelton. 2005. "Understanding the social costs of narcissism: The case of the tragedy of the commons." Personality and Social Psychology Bulletin 31(10): 1358-68.

Carney, Dana R., John T. Jost, Samuel D. Gosling, and Jeff Potter. 2008. "The Secret Lives of Liberals and Conservatives: Personality Profiles, Interaction Styles, and the Things They Leave Behind." Political Psychology 29(6): 807-40.

Cramer, Phebe. 1997. "Identity, personality, and defense mechanisms: An observer-based study." Journal of Research in Personality 31(1): 58-77.

Cushman, Philip. 1990. "Why the self is empty: Toward a historically situated psychology." American Psychologist 45(5): 599-611.

de Zavala, Agnieszka, Aleksandra Cichocka, and Michał Bilewicz. 2013. "The paradox of ingroup love: Differentiating collective narcissism advances understanding of the relationship between in-group and out-group attitudes." Journal of Personality 81(1): 1628. 


\section{Narcissism and Political Orientations}

de Zavala, Agnieszka, Aleksandra Cichocka, Roy Eidelson, and Nuwan Jayawickreme. 2009. "Collective narcissism and its social consequences." Journal of Personality and Social Psychology 97(6): 1074.

Deary, Ian J, G David Batty, and Catharine R Gale. 2008. "Bright children become enlightened adults." Psychological Science 19(1): 1-6.

Devine, Christopher J. 2015. "Ideological social identity: Psychological attachment to ideological in-groups as a political phenomenon and a behavioral influence." Political Behavior 37(3): 509-35.

Duckitt, John. 2001. "A dual-process cognitive-motivational theory of ideology and prejudice." Advances in experimental social psychology 33: 41-114.

Economist. 2016a. "Normalising narcissism." Economist 420(9003): 30.

Economist. 2016b. "Yes, I'd lie to you; The post-truth world." Economist 420(9006): 17-20.

Eidelman, Scott, Christian Crandall, Jeffrey Goodman, and John Blanchar. 2012. "Low-Effort Thought Promotes Political Conservatism." Personality and Social Psychology Bulletin 38(6): 808-20.

Emmons, R.A. 1984. "Factor analysis and construct validity of the Narcissistic Personality Inventory." Journal of Personality Assessment 48(3): 291-300.

Emmons, R.A. 1987. "Narcissism: theory and measurement." Journal of Personality and Social Psychology 52(1): 11-7.

Foster, Joshua D, W Keith Campbell, and Jean M Twenge. 2003. "Individual differences in narcissism: Inflated self-views across the lifespan and around the world." Journal of Research in Personality 37(6): 469-86.

Furedi, Frank. 2016. What's Happened To The University?: A sociological exploration of its infantilisation: Routledge.

Gelman, Andrew, and Jennifer Hill. 2007. Data analysis using regression and multilevel/hierarchical models: Cambridge University Press.

Gentile, Brittany, Joshua D Miller, Brian J Hoffman, Dennis E Reidy, Amos Zeichner, and W Keith Campbell. 2013. "A test of two brief measures of grandiose narcissism: The Narcissistic Personality Inventory-13 and the Narcissistic Personality Inventory-16." Psychological Assessment 25(4): 1120.

Ghorbani, Nima, PJ Watson, Stephen W Krauss, Mark N Bing, and H Kristl Davison. 2004. "Social science as dialogue: Narcissism, individualist and collectivist values, and religious interest in Iran and the United States." Current Psychology 23(2): 111-23.

Glasser, Susan. 2016. Covering Politics in a" Post-Truth" America: Brookings Institution Press.

Gore, Al. 2006. An inconvenient truth: The planetary emergency of global warming and what we can do about it. New York: Rodale.

Haidt, Jonathan, and Jesse Graham. 2007. "When Morality Opposes Justice: Conservatives Have Moral Intuitions that Liberals may not Recognize." Social Justice Research 20(1): 98-116.

Hardin, Garrett. 1968. "The Tragedy of the Commons." Science 162: 1243-48.

Hatemi, Peter K, Charles Crabtree, and Rose McDermott. 2017. "The relationship between sexual preferences and political orientations: Do positions in the bedroom affect positions in the ballot box?". Personality and Individual Differences 105: 318-25.

Hatemi, Peter K., and Rose McDermott. 2016. "Give Me Attitudes." Annual Review of Political Science 19: 331-50. 


\section{Narcissism and Political Orientations}

Hepper, Erica G, Richard H Gramzow, and Constantine Sedikides. 2010. "Individual differences in self-enhancement and self-protection strategies: An integrative analysis." Journal of personality 78(2): 781-814.

Hofstadter, Richard. 2011 (1960). The age of reform. New York: Vintage.

Inglehart, Ronald. 1977. The silent revolution: changing values and political styles among Western publics. Princeton, NJ: Princeton University Press.

Inglehart, Ronald. 1990. Culture Shift in Advanced Industrial Societies. Princeton, NJ: Princeton University Press.

Iyengar, Shanto, and Sean J. Westwood. 2015. "Fear and Loathing Across Party Lines: New Evidence on Group Polarization." American Journal of Politcal Science 59(3): 690-707.

Janoff-Bulman, Ronnie. 2009. "To provide or protect: Motivational bases of political liberalism and conservatism." Psychological Inquiry 20(2-3): 120-28.

Jost, John T., Jaime L. Napier, Hulda Thorisdottir, Samuel D. Gosling, Tibor P. Palfai, and Brian Ostafin. 2007. "Are Needs to Manage Uncertainty and Threat Associated With Political Conservatism or Ideological Extremity?". Personality and Social Psychology Bulletin 33(7): 989-1007.

Kanazawa, Satoshi. 2010. "Why liberals and atheists are more intelligent." Social Psychology Quarterly 73(1): 33-57.

Kernberg, Otto F. 1986. "Narcissistic personality disorder." In The Personality Disorders and Neuroses, eds. AA Cooper, AJ Frances and HM Sachs. New York: Basic Books. 21931.

Keyes, Ralph. 2004. The post-truth era: Dishonesty and deception in contemporary life. New York: Macmillan.

Klar, Samara. 2014. "A multidimensional study of ideological preferences and priorities among the American public." Public Opinion Quarterly 78(S1): 344-59.

Konrath, Sara, Brian P Meier, and Brad J Bushman. 2014. "Development and validation of the single item narcissism scale (SINS)." PLOS one 9(8): e103469.

Lakoff, George. 2010. Moral politics: How liberals and conservatives think: University of Chicago Press.

Lambe, Sinead, Catherine Hamilton-Giachritsis, Emily Garner, and Julian Walker. 2016. "The Role of Narcissism in Aggression and Violence A Systematic Review." Trauma, Violence, \& Abuse: 1-22.

Lasch, Christopher. 1979. The culture of narcissism: American life in an age of diminishing expectations: WW Norton.

Lasswell, Harold D. 1965. World politics and personal insecurity. New York, NY: Free Press. Lilla, Mark. 2016. The Shipwrecked Mind: On Political Reaction: New York Review Books.

Lukianoff, Greg, and Jonathan Haidt. 2015. "The coddling of the American mind." The Atlantic 1: 09-15.

McAdams, Dan. 2016. "The Mind of Donald Trump." The Atlantic Jun: 76-90.

McLaughlin, Eliott. 2017. "War on campus: The escalating battle over college free speech." http://www.cnn.com/2017/04/20/us/campus-free-speech-trnd/. (Mon May 1, 2017).

Miller, Joshua D, Brian J Hoffman, Eric T Gaughan, Brittany Gentile, Jessica Maples, and W Keith Campbell. 2011. "Grandiose and vulnerable narcissism: A nomological network analysis." Journal of Personality 79(5): 1013-42.

Morf, Carolyn C, Stephan Horvath, and Loredana Torchetti. 2011. "Narcissistic selfenhancement." Handbook of self-enhancement and self-protection: 399-424. 


\section{Narcissism and Political Orientations}

Müller, Jan-Werner. 2017. What is Populism? PA: University of Pennsylvania Press.

Newman, George, Paul Bloom, and Joshua Knobe. 2014. "Value judgments and the true self." Personality and Social Psychology Bulletin 40(2): 203-16.

Post, Jerrold M. 1993. "Current Concepts of the Narcissistic Personality: Implications for Political Psychology." Political Psychology 14(1): 99-121.

Pratto, Felicia, Jim Sidanius, Lisa M. Stallworth, and Bertram F. Malle. 1994. "Social dominance orientation: A personality variable predicting social and political attitudes." Journal of Personality and Social Psychology 67(4): 741-63.

Raskin, R, and CS Hall. 1981. "The Narcissistic Personality Inventory: alternative form reliability and further evidence of construct validity." Journal of Personality Assessment 45(2): 159-62.

Raskin, R, and H Terry. 1988. "A principal-components analysis of the Narcissistic Personality Inventory and further evidence of its construct validity." Journal of Personality and Social Psychology 54(5): 890-902.

Rhodewalt, Frederick, and Carolyn C Morf. 1995. "Self and interpersonal correlates of the Narcissistic Personality Inventory: A review and new findings." Journal of Research in Personality 29(1): 1-23.

Rothman, Stanley, and S Robert Lichter. 1985. "Personality, ideology and world view: A comparison of media and business elites." British Journal of Political Science 15(01): $29-49$.

Stenner, Karen. 2005. The Authoritarian Dynamic. New York: Cambridge University Press.

Toner, Kaitlin, Mark Leary, Michael Asher, and Katrina Jongman-Sereno. 2013. "Feeling superior is a bipartisan issue extremity (not direction) of political views predicts perceived belief superiority." Psychological Science 24(12): 2454-62.

Trzesniewski, Kali H, M Brent Donnellan, and Richard W Robins. 2008. "Do today's young people really think they are so extraordinary? An examination of secular trends in narcissism and self-enhancement." Psychological Science 19(2): 181-88.

Twenge, Jean M, and W Keith Campbell. 2009. The narcissism epidemic: Living in the age of entitlement. New York: Simon and Schuster.

Twenge, Jean M, and Joshua D Foster. 2010. "Birth cohort increases in narcissistic personality traits among American college students, 1982-2009." Social Psychological and Personality Science 1(1): 99-106.

Volokh, Eugene. 2015. "UC teaching faculty members not to criticize race-based affirmative action, call America 'melting pot,' and more." Washington Post, June 16. 16.

Watts, Ashley L, Scott O Lilienfeld, Sarah F Smith, Joshua D Miller, W Keith Campbell, Irwin D Waldman, Steven J Rubenzer, and Thomas J Faschingbauer. 2013. "The DoubleEdged Sword of Grandiose Narcissism Implications for Successful and Unsuccessful Leadership Among US Presidents." Psychological Science 24(12): 2379-89.

Weissflog, Meghan, Becky Choma, Jane Dywan, Stefon van Noordt, and Sidney Segalowitz. 2013. "The political (and physiological) divide: Political orientation, performance monitoring, and the anterior cingulate response." Social Neuroscience 8(5): 434-47.

Wetzel, Eunike, Anna Brown, Patrick L Hill, Joanne M Chung, Richard W Robins, and Brent W Roberts. 2017. "The narcissism epidemic is dead; long live the narcissism epidemic." Psychological Science 28(12): 1833-47.

Wolfe, Tom. 1976. "The me decade and the third great awakening." New York Magazine 23: 26-40. 
Narcissism and Political Orientations

Table 1. Hypothesized Relationships between Political Orientations and Narcissism

\begin{tabular}{|c|c|c|c|c|c|}
\hline \multirow[b]{2}{*}{ Narcissistic Facets } & \multicolumn{5}{|c|}{ Political Orientations } \\
\hline & $\begin{array}{c}\text { Out-Group } \\
\text { (Immigration/Refugees) }\end{array}$ & $\begin{array}{c}\text { Economic } \\
\text { (Public Spending) }\end{array}$ & $\begin{array}{c}\text { Social } \\
\text { (Guns/Policing) }\end{array}$ & $\begin{array}{l}\text { Self-Report } \\
\text { Ideology }\end{array}$ & $\begin{array}{c}\text { Party } \\
\text { Identification }\end{array}$ \\
\hline Authority seeking & - & - & - & - & - \\
\hline Self-sufficiency & Con & Con & - & Con & Rep \\
\hline Vanity & - & - & - & - & - \\
\hline Superiority & - & - & - & - & - \\
\hline Exploitativeness & - & - & - & - & - \\
\hline Entitlement & Con & Con & Con & Con & Rep \\
\hline Exhibitionism & Lib & Lib & - & Lib & Dem \\
\hline
\end{tabular}

Notes: "Con" refers to more conservative; "Rep" refers to Republican; "Lib" refers to more liberal; "Dem" to Democratic; "-" reflects no hypothesized difference between left and right orientations- this could be because both left and right orientations are equally likely to be associated with the narcissistic facet, or not at all. 
Narcissism and Political Orientations

Table 2: Ideology and Party ID measures - sample answer options and descriptive statistics

\begin{tabular}{|c|c|c|c|c|}
\hline Measure & Responses & $\begin{array}{c}\text { Mean (SD) or } \\
\text { percentage }\end{array}$ & $\begin{array}{c}\text { Valid } \\
\mathbf{N}\end{array}$ & Model \\
\hline $\begin{array}{r}\text { Self-reported } \\
\text { ideology (ANES } \\
/ \text { YouGov) }\end{array}$ & $\begin{array}{l}\text { (1) Very liberal to } \\
\text { (5) Very conservative }\end{array}$ & $3.04(1.23)$ & 705 & $\begin{array}{r}\text { Linear (through } \\
\text { OLS) }\end{array}$ \\
\hline $\begin{array}{l}\text { Economy } \\
\text { (YouGov) }\end{array}$ & $\begin{array}{r}\text { (1) Raise taxes } \\
\text { (2) Both cut spending and raise taxes } \\
\text { (3) Cut spending }\end{array}$ & $\begin{array}{l}13 \\
36 \\
51\end{array}$ & 649 & $\begin{array}{r}\text { Ordered Logit } \\
\text { (Maximum } \\
\text { Likelihood) } \\
\end{array}$ \\
\hline Immigrants (ANES) & $\begin{array}{l}\text { They should be } \\
\text { (1) allowed to stay in the U.S. and } \\
\text { eventually apply for citizenship } \\
\text { (2) allowed to stay in the U.S. but not get } \\
\text { citizenship } \\
\text { (3) be required to leave the U.S. }\end{array}$ & $\begin{array}{l}10 \\
40\end{array}$ & 747 & $\begin{array}{r}\text { Ordered Logit } \\
(\mathrm{ML})\end{array}$ \\
\hline Refugees (ANES) & $\begin{array}{l}\text { (1) Favor a great deal to } \\
\text { (7) Oppose a great deal }\end{array}$ & $4.53(2.21)$ & 745 & $\begin{array}{r}\text { Linear (through } \\
\text { OLS) }\end{array}$ \\
\hline $\begin{array}{r}\text { Gun control } \\
\text { (ANES) }\end{array}$ & $\begin{array}{r}\text { (1) Guns should be banned completely to } \\
\text { (5) There should be no restriction on gun } \\
\text { ownership }\end{array}$ & $2.67(1.07)$ & 726 & $\begin{array}{r}\text { Linear (through } \\
\text { OLS) }\end{array}$ \\
\hline Police (Rasmussen) & $\begin{array}{r}\text { (0) Police discrimination a. minorities } \\
\text { (1) Level of crime in low-income inner-city } \\
\text { communities }\end{array}$ & $\begin{array}{l}28 \\
72\end{array}$ & 740 & $\begin{array}{r}\text { Binomial Logit } \\
(\mathrm{ML})\end{array}$ \\
\hline $\begin{array}{r}\text { Party ID } \\
\text { (ANES/YouGov) }\end{array}$ & $\begin{array}{l}\text { (1) Strong Democrat to } \\
\text { (7) Strong Republican }\end{array}$ & $3.7(2.19)$ & 732 & $\begin{array}{r}\text { Linear (through } \\
\text { OLS) }\end{array}$ \\
\hline Party ID recoded & $\begin{array}{r}\text { Democrat (includes Strong and not very } \\
\text { strong) } \\
\text { Independent } \\
\text { Republican (includes Strong and not very } \\
\text { strong) }\end{array}$ & $\begin{array}{l}47 \\
16 \\
37\end{array}$ & 732 & $\begin{array}{r}\text { Ordered Logit } \\
(\mathrm{ML})\end{array}$ \\
\hline
\end{tabular}

Note: Republican sample size share was rounded to 37 not 36 so that the total for party ID (recoded) adds up to $100 \%$. 


\section{Narcissism and Political Orientations}

Figure 1: Narcissism coefficient plot (socio-demographic controls)
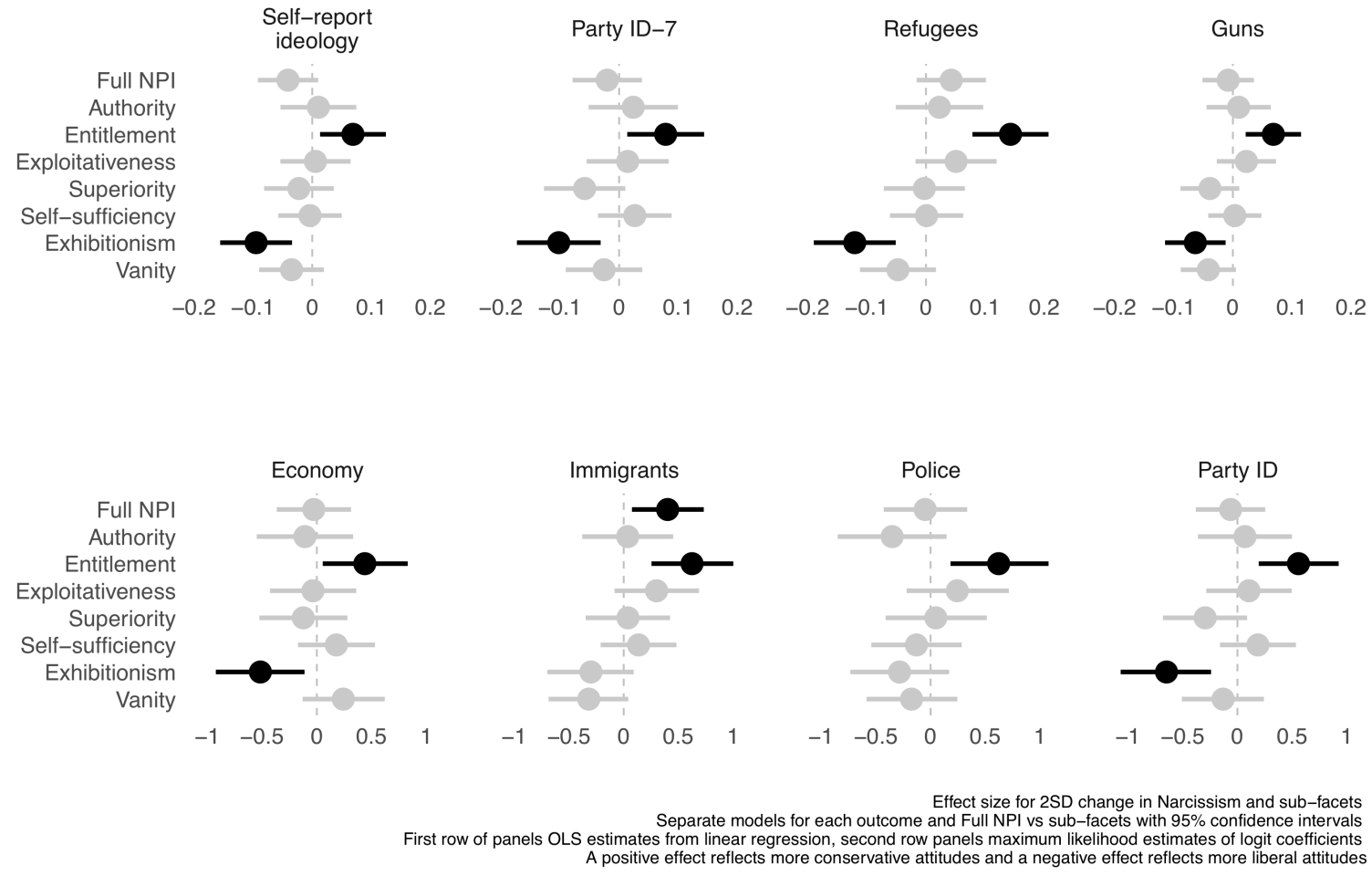
Narcissism and Political Orientations

Figure 2: Hierarchical models (socio-demographic controls)

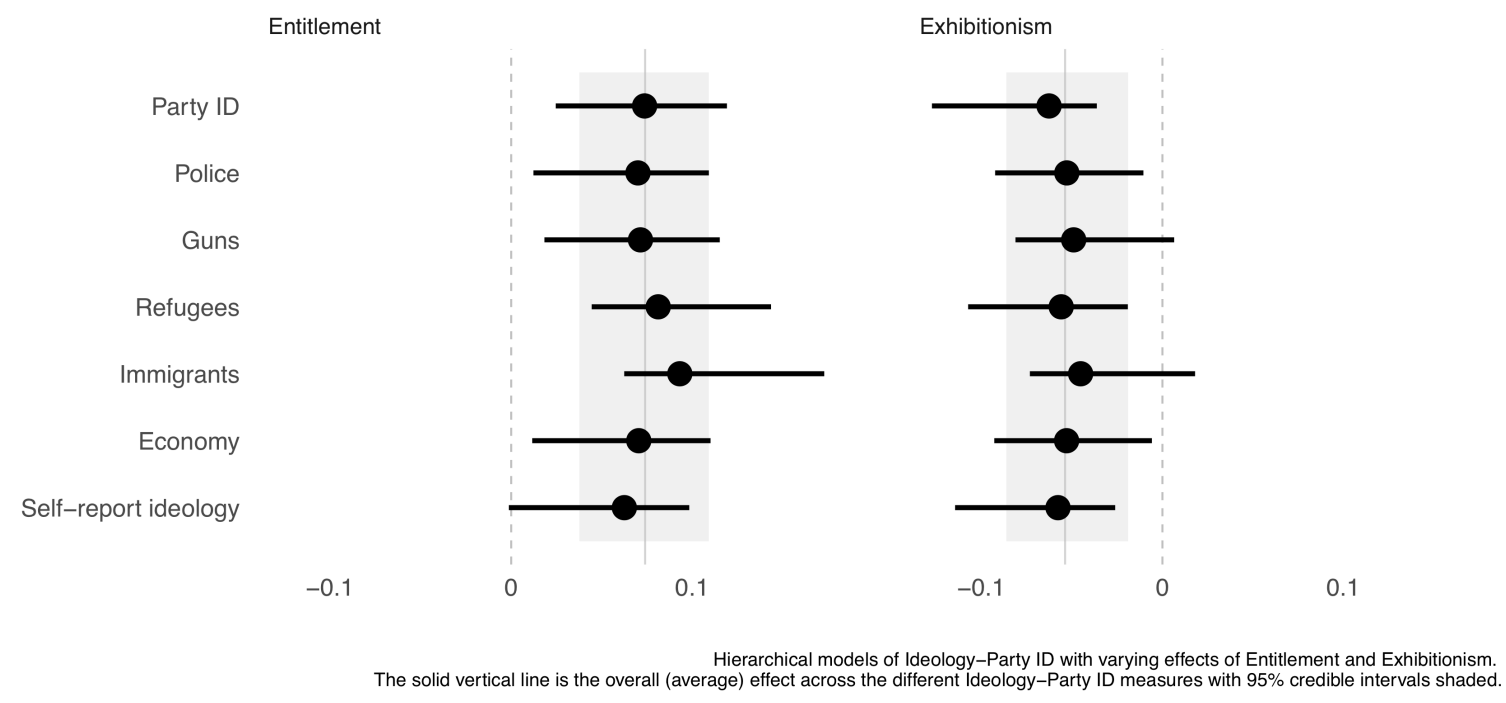




\section{Narcissism and Political Orientations}

Figure 3: Narcissism coefficient plot (all controls)
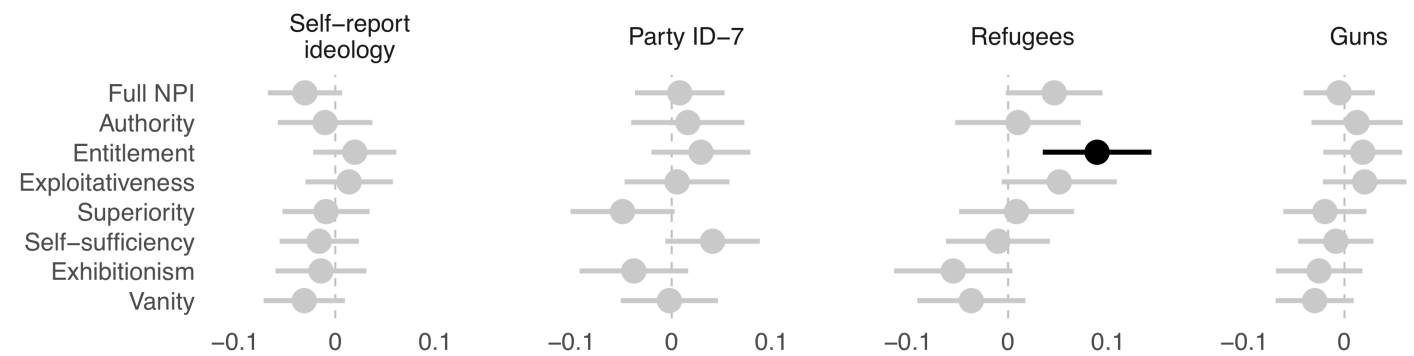

0.1

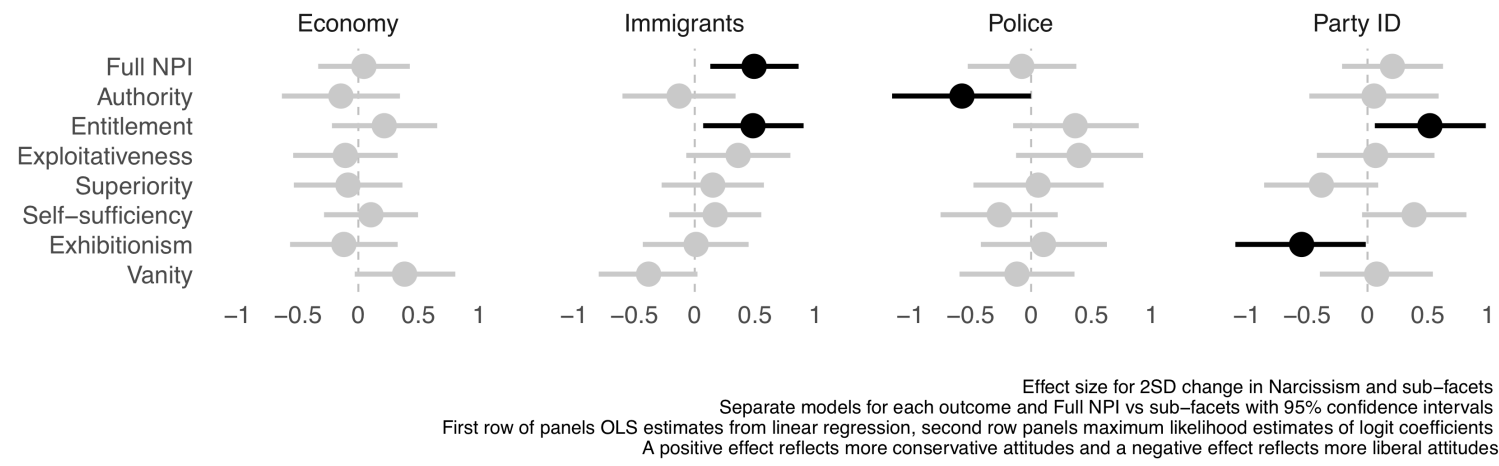


Narcissism and Political Orientations

Figure 4: Hierarchical models (all controls)

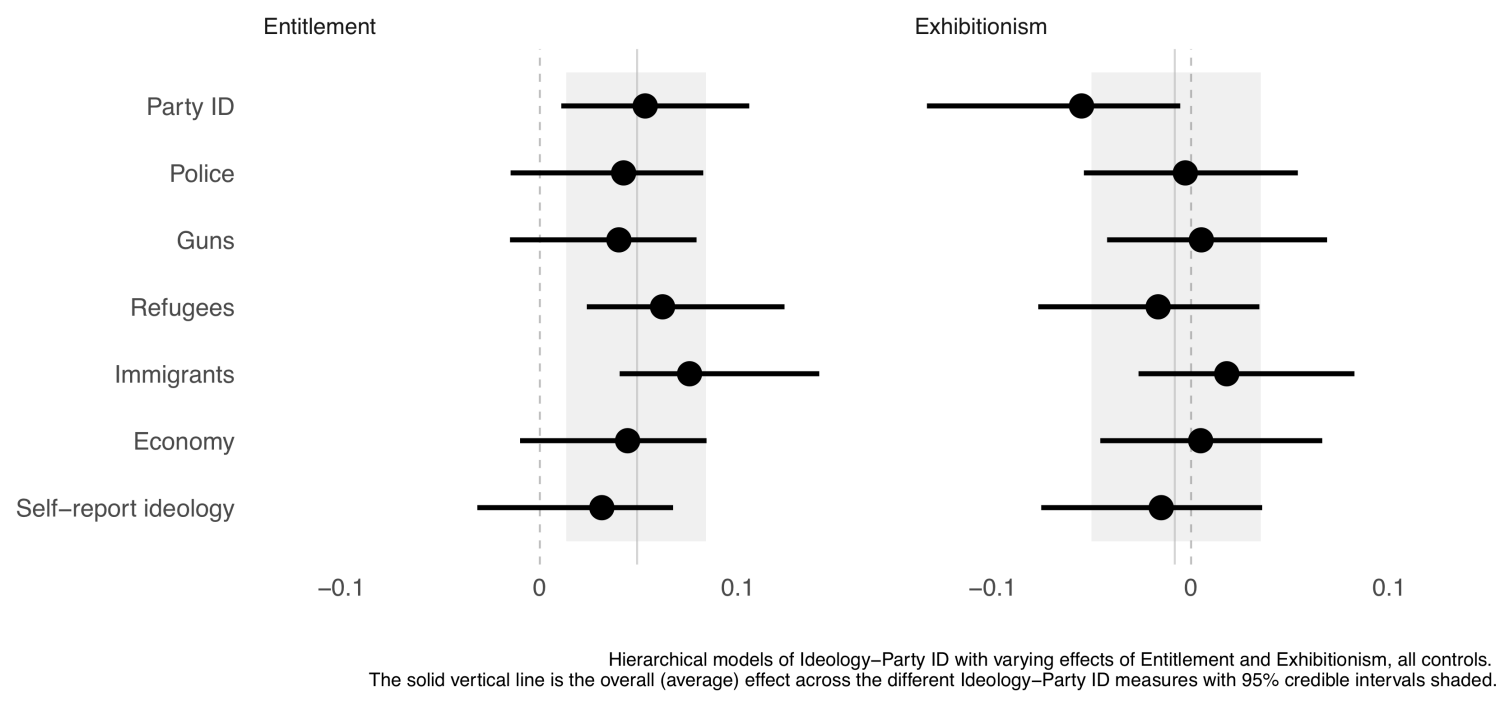




\section{Narcissism and Political Orientations}

Figure 5: Multinomial logistic regressions of Entitlement and political attitudes
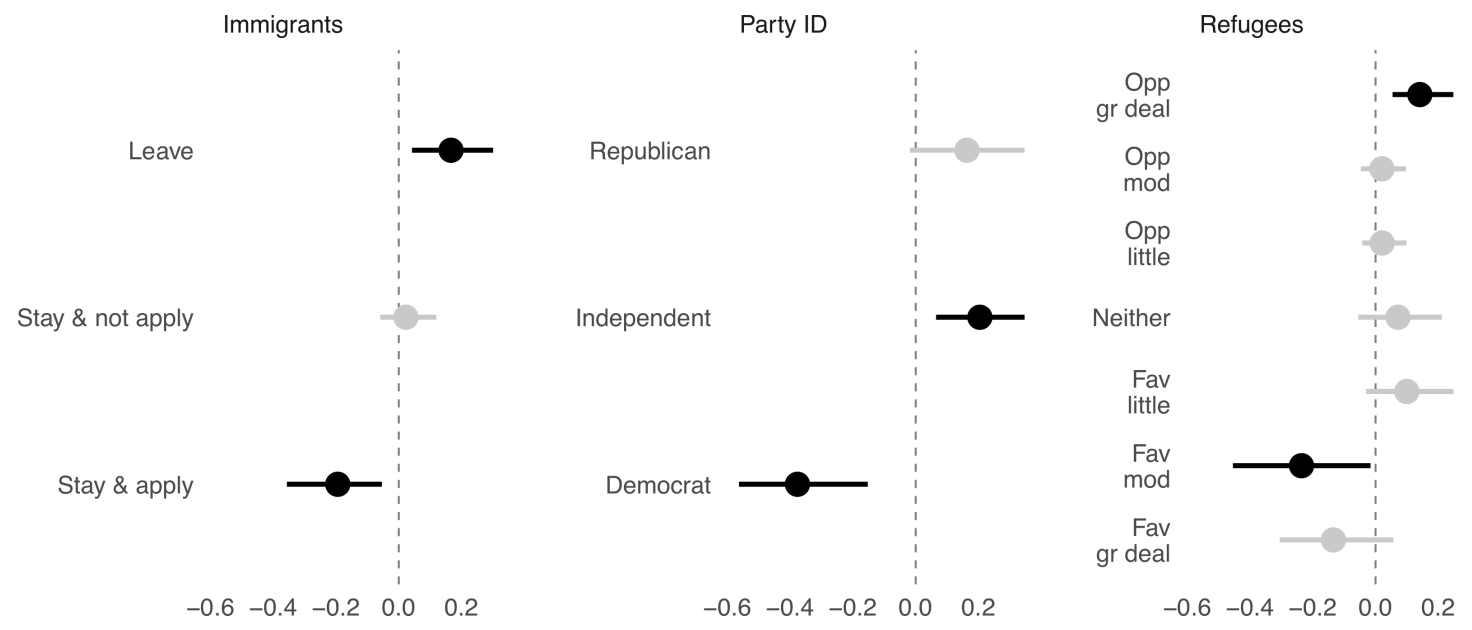

First difference: from $2 \mathrm{SD}$ below the mean to $2 \mathrm{SD}$ above mean in Entitlement 